\title{
A survey on orthopedic injuries during a marathon sled dog race
}

This article was published in the following Dove Press journal:

Veterinary Medicine: Research and Reports

20 October 2015

Number of times this article has been viewed

\section{Dirsko JF von Pfeil ${ }^{1,2}$ \\ William D Liska ${ }^{3}$ \\ Stuart Nelson, $\mathrm{Jr}^{4}$ \\ Sabine Mann ${ }^{5}$ \\ Joseph J Wakshlag6}

'Friendship Surgical Services of the Friendship Hospital for Animals, Washington, DC, ${ }^{2}$ Department of Small Animal Clinical Sciences, College of Veterinary Medicine, Michigan State University, East Lansing, MI, ${ }^{3}$ Global Veterinary Specialists, Sugar Land, TX, ${ }^{4}$ The Iditarod Headquarters, Wasilla, AK, ${ }^{5}$ Department of Population Medicine, ${ }^{6}$ Department of Clinical Sciences, College of Veterinary Medicine, Cornell University, Ithaca, NY, USA
Correspondence: Dirsko JF von Pfeil Friendship Surgical Services of the Friendship Hospital for Animals, 4105 Brandywine Street NW, Washington, DC 20016, USA

Tel +l 2023637300

Fax +I 2023637126

Email dvpfeil@yahoo.com
Purpose: This prospective observational study aimed to describe and quantify orthopedic injuries (OI) during a marathon sled dog race that led to discontinuation of racing (dropped dogs [DDs]) and to suggest potential associations with risk factors during the event.

Study design: Prospective observational study.

Animals: A total of 989 Nordic breed endurance sled dogs that participated in the 2011 Iditarod Sled Dog Race. Data were collected via an extensive questionnaire, medical records, and speed calculations based on Global Positioning System equipment on each dog sled. OI risk factors and DD incidence were statistically analyzed on dogs and teams completing at least half the race distance, including Student's $t$-test, Pearson's chi-squared test, Poisson regression, and various frailty analysis models as indicated. Significance was set at $P<0.10$ for inclusion in the models with trends established at $P \leq 0.10$ and significance declared at $P<0.05$.

Results: Questionnaire response was $40.3 \%$. DD incidence was $38.3 \%$, most often due to OI (50.6\%). OI occurred most frequently in the thoracic limb (43.3\%) compared with pelvic limb injuries (7.3\%). Increased speed was associated with fewer shoulder injuries (Ratio $=0.65$, $P=0.03$ ). Carpal injuries were positively related with increased conditioning distance (defined as training miles; Hazard ratio $=1.61, P=0.02$ ). The risk to become a DD decreased with every year of increased age of the dogs (Hazard ratio $=0.92, P=0.03$ ).

Conclusion: OI, specifically of the shoulder and carpus, are common in marathon sled dogs. Injury risk may be speed-related and decreases with increasing age of the dog. Further study of environmental, dietary, and trail conditions in sled dog racing orthopedic research is needed.

Keywords: veterinary sports medicine, endurance, canine, athlete, Iditarod, arctic

\section{Introduction}

The Iditarod Sled Dog Race is a long-distance race of dog teams in Alaska spanning approximately 1,600 km from Anchorage to Nome. ${ }^{1}$ All mushers participating in this race must qualify through successful completion of other distance races and are considered professional participants with extensive training and conditioning that for most teams begins approximately 9 months prior to the race itself. Teams consist of a maximum of $16 \mathrm{dogs}$, all starting the race on day 1 . Most teams finish the race distance in 8-14 days with mandatory stops at 21-24 checkpoints, depending on the route for a particular year. ${ }^{2}$ The fastest teams travel on average approximately $180 \mathrm{~km}$ per day.

Veterinary care is provided by approximately 50 trained volunteer trail veterinarians who perform routine examinations, evaluations, and treatments as needed at each checkpoint. ${ }^{3}$ Medical abnormalities, treatment recommendations, and general comments are documented as a "Dog Team Diary". When indicated, dogs are dropped from the team in competition. Dropped dogs (DDs) are cared for as needed in the checkpoints 
by the veterinary team and then flown back to Anchorage where they are reunited with the mushers' dog handlers. In addition to the "Dog Team Diary", a "Dropped Dog Form" must accompany all DDs, and it serves as medical record. This form must be completed by checkpoint veterinarians and lists the reasons for dropping a dog, as well as any additional abnormalities that may be identified by a veterinary exam. Dropping dogs from the team is an effective method to prevent major injury and overexertion. DDs typically return to racing activity once recovered but cannot be reunited with the team in the same race. Also, dogs cannot be added to the team after the start, and teams must finish the race with a minimum of six dogs. ${ }^{4}$ Orthopedic injuries (OI) are anecdotally listed as the most common reason for DDs during marathon sled dog races. However, in the past 22 years, only one study has been performed to classify injuries in long-distance sled dog racing..$^{5}$ Therefore, a prospective observational study was conducted during the 2011 Iditarod Sled Dog Race with the objective to describe the frequency of lesions from DDs during a marathon sled dog race and associated risk factors, as well as the utilization of a musher survey to provide information related to care and training as a baseline assessment for future research in this field.

\section{Materials and methods}

The study was approved by the Iditarod Trail Committee for 2011. A nonvalidated basic questionnaire (Figure S1) was developed based on the experience of the authors during previous races regarding data collected that would be relevant to understanding common practices that might be related to dogs being discontinued from racing, particularly due to orthopedic reasons. Survey data were collected prior to, during, and after the Iditarod Sled Dog Race, between March 3, 2011 and June 20, 2011.

Prior to the race, mushers were informed about the study via email, and in person at the mandatory prerace meeting. Mushers signed a written informed consent form regarding the use of the questionnaire information that was distributed twice prior to as well as immediately after the race. If indicated, a maximum of three reminders to complete the questionnaire were mailed, faxed, and emailed, respectively, to the mushers in addition to a maximum of three personal phone calls, during the 12 weeks after the race ended. Participation was voluntary, and confidentiality was assured. Mushers completing the questionnaire were defined as participants and the ones not completing it as nonparticipants.

During the race, as part of the race rules, all mushers were required to permit attachment of Global Positioning System
(GPS) units (IonEarth Global Position Tracking. Microline Technology Corporation, Traverse City, MI, USA) to each team's sled, and GPS speed records were used in this study. GPS data were logged every 15 minutes for the duration of the race with a maximum of 120,000 recordings. Rest time and transportation data were excluded; so, only the time when the sled was actually moving on the trail was used to calculate the median speed. Records of veterinary medical abnormalities, including OI and reasons for DDs, were submitted to the investigators immediately after the race. Although additional data were collected with the used questionnaire, to remain in the scope of this study, only OI for DDs were described and analyzed. All collected data were entered into a data management program (Microsoft Excel 2010, Microsoft Corporation, Redmond, WA, USA).

\section{Statistical analysis}

Figure 1 depicts the flowchart of number of dogs included in the analysis. Analysis of differences in baseline characteristics were used to test for discrepancies between teams that agreed to participate in the questionnaire and those that did not to investigate a possible bias among both populations of teams. The DDs variables included number of dogs on the team, sex, number of male dogs on the team, reason for being dropped, if it was the musher's first Iditarod race or not, completion of over half of the race or not, top ten race finisher, and top 20 race finisher. Pearson's chi-squared tests were used to assess the relationship between categorical variables while continuous parameters such as dog's age, median team speed, and median speed before becoming a DDs were analyzed using $t$-tests (JMP version 11.0; SAS Institute, Cary, NC, USA).

Since the objective of this study was to describe the influence of race conditions on the risk of injury, teams that did not complete at least half of the race distance were excluded from further statistical modeling (Poisson and frailty models). Time at risk would have been greatly reduced for any injury or reason to be dropped if these teams would have been included into the statistical model. Each dog that was dropped during the race was assigned a single reason for leaving the race, and this reason was documented in the medical record by the veterinarian when the dog became a DD. Because of the hierarchical nature of the data (team-level and dog-level data), we analyzed the data in two steps. Team-level predictors tested included the following categorical variables: rookie in the year of 2011 (yes/no), full-time musher (yes/no), goal for the race (top 5, top 10, top 30, or finisher), and team leasing dogs (yes/no). Continuous team-level data included median speed of the 


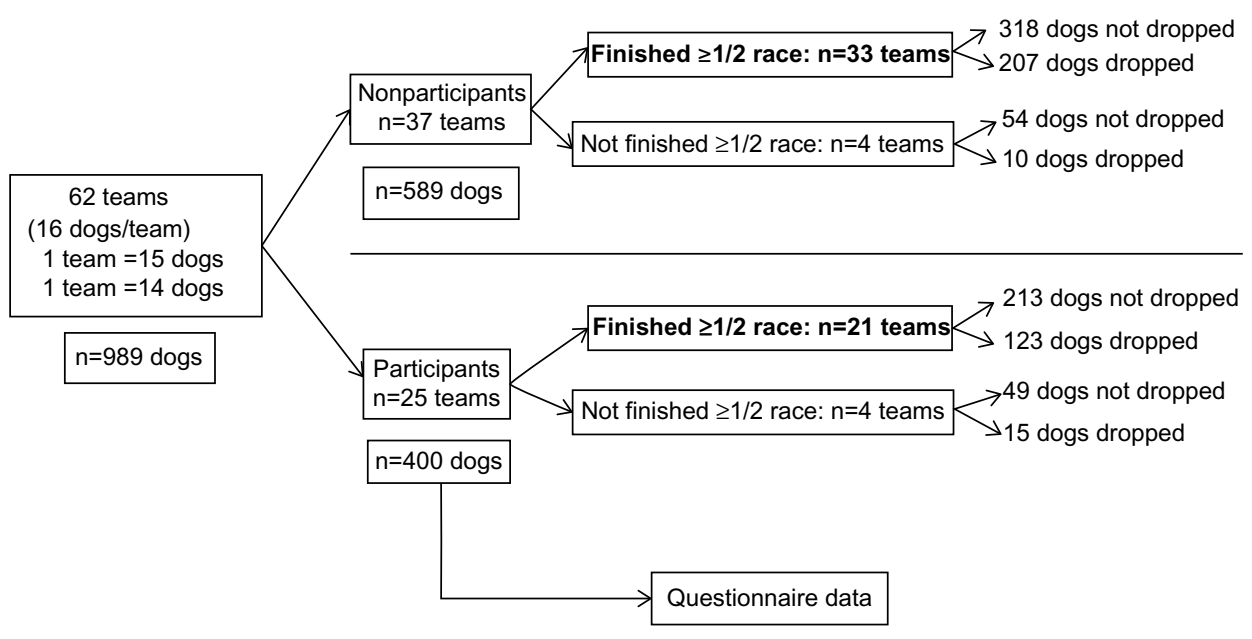

Figure I Flowchart of the study.

Note: Bold font indicate teams included into statistical models.

team, musher age, years of experience, kilometers of prerace conditioning, current season race kilometers, number of long-distance race competitions entered in the current season, conditioning/training time for the 2011 Iditarod (weeks), intensive training weeks prior to the race, time used for injury prevention, and time used for injury treatment.

\section{Poisson model}

The effects of team-level data on the number of dogs dropped for any reason or for carpus, shoulder, and pelvic limb injury were analyzed with a Poisson regression model (Proc GENMOD in SAS, version 9.3; SAS Institute, Cary, $\mathrm{NC}$ ). In a first step, each predictor was tested in a univariable model. Predictors with a $P$-value of $<0.20$ were included in the initial multivariable model. Predictors were removed from the model in a backward stepwise manner until remaining predictors had a $P$-value of $<0.10$. Over-dispersion of the model was assessed and a negative binomial distribution was chosen if over-dispersion was present and residual diagnostics of raw, Pearson, and Deviance residuals were carried out after each model fit. The presence of potential outliers was assessed with Cook's distance (outliers defined as any Cook's distance $>0.5)$.

\section{Frailty analysis}

Dog-level data (measurements that were taken on the level of the dog as opposed to the level of the team) were analyzed with a proportional hazards model (Proc PHREG in SAS, version 9.3; SAS Institute, Cary, NC), ties were handled with the Efron method, and team was included as a random effect. Time to being dropped was expressed as kilometers (in increments of $100 \mathrm{~km}$ ) raced as this information was more detailed than days in race (several checkpoints were passed in a day). Categorical variables tested in the model included sex of the dog and previous injury of dog (yes/no) and trail condition (no snow, hard-packed snow, soft snow, open water, ice, other) before being dropped. Continuous variables tested included age of dog (years), median speed of team overall, median speed of team before dog was dropped, prerace training kilometers, and current season race kilometers. Model building was carried out as described earlier, and one model each was done for dogs belonging to participating teams only and all dogs in the race. Final results reported include all predictors retained in the model at $P<0.10$. Each final model was assessed for the proportionality assumption (ASSESS statement in Proc PHREG of SAS, SAS Institute, Cary, NC), and model fit was accepted if none of the predictor variables violated the Kolmogorov-type supremum test at a level of less than 0.05 .

\section{Results}

The entire field at race start consisted of 62 teams, all but two with 16 dogs. One team had 15 dogs, and another team had 14 dogs. The entire field consisted of 989 dogs. Data was evaluated on 861 dogs. Of these 330 (38.3\%) were DDs. Of these DD, 167 (50.6\%) discontinued the race for OI.

Of all teams, $3.2 \%, 1.6 \%, 3.2 \%, 9.7 \%, 9.7 \%, 12.9 \%$, and $16.1 \%$ dropped zero, one, two, three, four, five, or six dogs, respectively. The majority of teams $(22.6 \%)$ dropped seven dogs, and $21.0 \%$ of all teams dropped eight, nine, or ten dogs. Of all 62 teams, 25 mushers (40.3\%) agreed to participate in the questionnaire and 37 did not. Of the participants, 21 teams finished at least half the race distance and four did not. Three of these four teams discontinued the race for musher injury or 
illness, not because of injured dogs; one musher decided to scratch because that musher had run out of lead dogs. These four teams were excluded from statistical analysis. Of the 37 teams that did not participate in the questionnaire, 33 teams finished half the race distance.

\section{Entire population of dogs completing over half of the race}

Age and number of DDs

The racing dogs' age ranged from 1 year to 11 years, with the majority of dogs being 2-6 years old. More details are available in Table 1.

\section{Trail conditions}

There was no trend toward increased DDs with any particular trail condition as assessed by mushers. According to the assessment of all participating mushers, the majority of the trail was hard-packed snow (mean\% [SD] =77.1 [9.4]), followed by soft snow (mean $\%$ [SD] $=16.9$ [7.4]). Absence of snow, open water/overflow, and bare ice were rare conditions on the trail (mean\% [SD] =1.9 [2.2], 1.9 [1.9], and 1.5 [1.6], respectively).

\section{Checkpoints}

There was a significant difference between numbers of DDs at specific checkpoints during the race $(P<0.0001)$. Although the majority of dogs were dropped in Nikolai, the distribution of reasons for DDs at this checkpoint was not different from all other checkpoints combined $(P=0.45$; Table 2 and Figure 2).

Table I Dog age and number of dogs dropped and percentage of all dogs in age group of all teams that finished half of the race including both participants and nonparticipants

\begin{tabular}{|c|c|c|c|c|c|}
\hline \multirow[t]{2}{*}{$\begin{array}{l}\text { Age } \\
\text { (years) }\end{array}$} & \multirow{2}{*}{$\begin{array}{l}\text { Number } \\
\text { of dogs } \\
\text { in race }\end{array}$} & \multicolumn{2}{|c|}{$\begin{array}{l}\text { Participants and } \\
\text { nonparticipants }\end{array}$} & \multicolumn{2}{|c|}{ Participants only } \\
\hline & & DD (\%) & $\begin{array}{l}\text { DD ortho } \\
\text { (\%) }\end{array}$ & DDs (\%) & $\begin{array}{l}\text { DDs ortho } \\
\text { (\%) }\end{array}$ \\
\hline 1 & 29 & $19(65.5)$ & II (37.9) & $10(34.5)$ & $6(20.7)$ \\
\hline 2 & 124 & $59(47.6)$ & $27(21.8)$ & $18(14.5)$ & $12(9.7)$ \\
\hline 3 & 196 & $71(36.2)$ & $31(15.8)$ & $24(12.2)$ & $7(3.6)$ \\
\hline 4 & 134 & $54(40.3)$ & $32(23.9)$ & $27(20.1)$ & $16(12.0)$ \\
\hline 5 & 121 & 39 (32.2) & $19(15.7)$ & $16(13.2)$ & $7(5.8)$ \\
\hline 6 & 109 & $39(35.8)$ & $22(20.2)$ & $15(13.8)$ & $8(7.4)$ \\
\hline 7 & 73 & $26(35.6)$ & $17(23.3)$ & $7(9.6)$ & $6(8.2)$ \\
\hline 8 & 53 & $15(28.3)$ & $7(13.2)$ & $5(9.4)$ & $3(5.7)$ \\
\hline $9-11$ & 24 & $8(33.3)$ & I (4.2) & I (4.I) & $0(0)$ \\
\hline Total & 861 & $330(38.3)$ & $167(19.4)$ & $123(14.3)$ & $65(7.5)$ \\
\hline
\end{tabular}

Abbreviations: DDs, dropped dogs; DDs ortho, dropped dogs for orthopedic reasons only (shoulder, carpus, and pelvic limb injuries).
Table 2 Dropped dogs per checkpoint for participating and nonparticipating teams that completed at least half of the race distance and dogs dropped for orthopedic reasons only

\begin{tabular}{llll}
\hline Checkpoint & $\begin{array}{l}\text { Distance from last } \\
\text { checkpoint } \mathbf{( k m )}\end{array}$ & DDs (\%) & DDs ortho (\%) \\
\hline Yentna station & 72 & $\mathrm{I}(0.3)$ & $\mathrm{I}(0.6)$ \\
Skwentna & 55 & $10(3.0)$ & $6(3.6)$ \\
Finger Lake & 72 & $20(6.1)$ & $13(7.8)$ \\
Rainy Pass & 48 & $27(8.2)$ & $17(10.2)$ \\
Rohn & 77 & $17(5.2)$ & $10(6.0)$ \\
Nikolai & $12 \mathrm{I}$ & $4 \mathrm{I}(12.4)$ & $20(12.0)$ \\
McGrath & 87 & $21(5.9)$ & $6(3.6)$ \\
Takotna & 29 & $9(2.5)$ & $2(1.2)$ \\
Ophir & 40 & $17(4.8)$ & $9(5.4)$ \\
Iditarod & 145 & $25(7.0)$ & $20(12.0)$ \\
Shageluk & 105 & $20(5.6)$ & $8(4.8)$ \\
Anvik & 40 & $11(3.1)$ & $6(3.6)$ \\
Grayling & 29 & $8(2.3)$ & $3(1.8)$ \\
Eagle Island & 97 & $17(4.8)$ & $7(4.2)$ \\
Kaltag & 113 & $17(4.8)$ & $7(4.2)$ \\
Unalakleet & 145 & $27(7.6)$ & $15(9.0)$ \\
Shaktoolik & 68 & $7(2.0)$ & $1(0.6)$ \\
Koyuk & 77 & $14(3.9)$ & $6(3.6)$ \\
Elim & 77 & $5(1.4)$ & $4(2.4)$ \\
White Mountain & 74 & $15(4.2)$ & $5(3.0)$ \\
Safety & 89 & $1(0.3)$ & $1(0.6)$ \\
& & $330(100.0)$ & $167(100.0)$ \\
\hline Notes: The & &
\end{tabular}

Notes: The distance from the previous checkpoint with the number and percentage of dropped dogs is shown.

Abbreviations: DDs, dropped dogs; DDs ortho, dropped dogs for orthopedic reasons only (shoulder, carpus, and hind limb injuries).

There were 27 DDs in Unalakleet of which 15 were dropped due to shoulder injury and 12 for all other reasons combined. This was compared with all other 20 checkpoints combined with 96 shoulder injuries $(P=0.008)$. Similarly, at Finger Lake, of the 24 dogs that were dropped from all teams,



Figure 2 Dogs dropped in relation to checkpoint and race kilometer between each checkpoint.

Note: Despite Rainy Pass seemingly associated with increased number of dropped dogs, no clinically relevant statistically significant correlation to all other factors evaluated could be made. 
14 listed shoulder as the reason, ten for all other reasons combined, compared with 97 dropped for shoulder injury at all other 20 checkpoints combined $(P=0.005)$.

When evaluating the number of DDs in relation to checkpoint and raced kilometers, no significant differences were detected (Figure 2) and no specific associations with all other evaluated factors were determined to drop a dog.

Descriptive evaluation of participating and nonparticipating teams can be found in Table 3. Age of dogs, speed of the team, sex of DDs, and reasons for dropping dogs did not differ between the two groups.

\section{Survival analysis of all teams}

When investigating the associations between the variables that were available for all teams (participants and nonparticipants), increased age of the dogs was found to have a protective effect for being dropped (ie, hazard ratio [HR] below 1.0) for any reason $(\mathrm{HR}=0.92$ [0.87-0.97], $P=0.003)$, as well as specifically for carpus injuries (HR $=0.84$ [0.71-0.98], $P=0.03)$, and shoulder injuries alone (HR $=0.91$ [0.82-1.00], $P=0.06)$. Females tended to be less likely to be dropped compared with males for shoulder injuries (HR $=0.70$ [0.46-1.07], $P=0.1)$.

\section{Participant's results}

The median number of marathon races in the participant's career was five (range $=1-20$ ), and the median number of long distance races was ten (range $=1-38$ ). Approximately half of the participants $(13 / 25,52 \%)$ considered themselves full-time mushers. The participants' goals at the start were to finish among the top five $(28 \%)$, top ten (8\%), top 30 $(36 \%)$, and just to finish the race $(28 \%)$. There were 16 male mushers and five female mushers whose questionnaire answers were included in the statistical analysis. Additional characteristics of participants are summarized in Table 4.

Of the 25 participants, eleven leased at least one dog, with the median number of dogs leased being five (range $=1-16$ ). Those participants who leased dogs spent a median time of 26 weeks working with those dogs (range $=1-64$ ). Four participants were excluded from the Poisson and frailty analysis because they did not complete at least half of the race distance and hence time at risk would have been greatly reduced for any injury or reason to be dropped.

\section{Injury prevention and treatment}

The median time spent by mushers on injury prevention was 20 minutes per team (range $=0-60$ minutes). The most commonly applied methods for injury prevention are listed in Table 5 and follow described recommendations. ${ }^{6,7}$ Several liniments were used frequently including ingredients such as hyperoxygenated peanut oil and rosemary oil extract (ALGYVAL, Massage Balm for Dogs; Alpine Outfitters, San Clemente, CA, USA), essential oil of wintergreen (Zalox; Ten Squared Racing, Two Harbors, MN, USA), peanut oil and rosemary (Accede, containing peanut oil and rosemary extracts; Ten Squared Racing, Two Harbors, MN, USA), and emu oil (Mushers First Aid, Mountain Ridge, Shirley Mills, MN, USA). Foot powders included menthol

Table 3 Drop reasons for teams finishing at least half race distance as well as age distribution and sex of dogs and speed of the team before being dropped

\begin{tabular}{|c|c|c|c|c|c|}
\hline & \multirow[t]{2}{*}{$\begin{array}{l}\text { Participating teams } \\
(n=2 I)\end{array}$} & \multirow[t]{2}{*}{$\begin{array}{l}\text { Nonparticipating } \\
\text { teams }(n=33)\end{array}$} & \multirow[t]{2}{*}{ P-value } & \multicolumn{2}{|c|}{$\begin{array}{l}\text { Total - all teams } \\
(n=54)\end{array}$} \\
\hline & & & & $\mathbf{N}$ & $\%$ \\
\hline Total number of dogs dropped/dogs in race (\%) & $123 / 336(36.6)$ & $207 / 525(39.4)$ & 0.41 & $330 / 861$ & 38.3 \\
\hline Median speed before being dropped $(\mathrm{km} / \mathrm{hr}) \pm \mathrm{SD}$ & $12.55 \pm 1.5 \mathrm{I}$ & $12.76 \pm 1.54$ & 0.23 & $12.63 \pm 1.53$ & \\
\hline Mean age of dropped dogs (years) $\pm S D$ & $4.0 \pm 1.9$ & $4.2 \pm 2.1$ & 0.37 & $4.2 \pm 2.0$ & \\
\hline Sex of dropped dogs/dogs in race (\%) & & & 0.09 & & \\
\hline Male & $78 / 209(37.3)$ & $150 / 353(42.5)$ & & $228 / 562$ & 40.6 \\
\hline Female & $45 / 127(35.4)$ & $57 / 172(33.1)$ & & $102 / 299$ & 34.1 \\
\hline \multicolumn{2}{|l|}{ Number of dogs dropped per category (\% of all dropped) } & & 0.23 & & \\
\hline Carpus & $17(13.8)$ & $26(12.6)$ & & $42 / 330$ & 12.7 \\
\hline Shoulder (biceps/triceps/pectoralis) & $38(30.9)$ & $67(32.4)$ & & $101 / 330$ & 30.6 \\
\hline $\begin{array}{l}\text { Skeletal pelvic limb (metatarsus, tarsus, } \\
\text { coxofemoral joint, femur, stifle) }\end{array}$ & $8(6.5)$ & $7(3.4)$ & & $15 / 330$ & 4.5 \\
\hline $\begin{array}{l}\text { Muscle/tendon: pelvic limb (Achilles tendon, } \\
\text { emitendinosus, semitendinosus, } \\
\text { gastrocnemius, quadriceps) }\end{array}$ & $2(1.6)$ & 8 (3.9) & & $9 / 330$ & 2.8 \\
\hline
\end{tabular}

Abbreviation: SD, standard deviation. 
Table 4 Characteristics of the mushers

\begin{tabular}{lllllll}
\hline & Age (years) & Years in sport & Prerace training km & $\begin{array}{l}\text { Current season } \\
\text { race km }\end{array}$ & $\begin{array}{l}\text { Preparation time } \\
\text { for Iditarod } \\
\text { (months/year) }\end{array}$ & $\begin{array}{l}\text { Highly intensive } \\
\text { prerace conditioning } \\
\text { and training (weeks) }\end{array}$ \\
\hline Mean \pm SD (range) & $41.7 \pm 10.3(2 \mid-61)$ & $7.4 \pm 6.0(1-19)$ & $\begin{array}{l}4,023.36 \pm 1,496.69 \\
(804.67-6,437.37)\end{array}$ & $\begin{array}{l}1,915.12 \pm 1,277.82 \\
(0-2,950)\end{array}$ & $6.4 \pm 4.3(0-12)$ & $13.5 \pm 7.2(0-25)$ \\
\hline
\end{tabular}

Abbreviation: SD, standard deviation.

(Gold Bond Blue Foot Powder; Chattem Inc., Chattanooga, TN, USA), and zinc oxide (Web-Med, containing zinc oxide; Mountain Ridge, Shirley Mills, MN, USA). Similar to injury prevention, injury treatments included the same strategies as prevention and varied widely. The median time used for injury treatment was 20 minutes per team (range $=5-60$ minutes). No statistically significant effect could be detected between methods applied for injury prevention and treatment because of the wide variety of variables, and the sample size was not sufficient to make statistical inferences. The most commonly applied methods for injury treatment are listed in Table 5.

\section{DD data}

The age of participants' racing dogs ranged from 1 year to 10 years, with most dogs being 2-5 years old. More details are available in Table 3.

\section{Poisson model of participating teams}

No significant associations with team-level predictors could be identified for pelvic limb injuries and fatigue. Leasing dogs tended to decrease the number of dogs dropped for any reasons compared with teams that did not lease dogs (Ratio $=0.73[95 \%$ CI $=0.51-1.04], P=0.09)$. Increasing the prerace training distance increased the number of dogs being dropped for carpus injuries (Ratio $=1.60[95 \%$ $\mathrm{CI}=1.02-2.48], P=0.04)$, while an increase in the number of intensive training weeks was associated with a slight decrease in the number of DDs (Ratio $=0.92$ [95\% CI $=0.86-0.98]$, $P=0.02)$. Increased median speed of a team was associated with a tendency toward fewer DDs for shoulder injuries (Ratio $=0.69$ [95\% CI $=0.47-1.05], P=0.03$ ). Similarly, completion of more races in the current season showed a trend to result in fewer DDs for shoulder injuries (Ratio $=0.96$ [95\% CI $=0.93-1.00], P=0.06)$.

Table 5 Injury prevention and treatment

\begin{tabular}{|c|c|}
\hline Anatomical location & Injury prevention or treatment measures applied \\
\hline Neck, shoulder, thoracic limb muscles & $\begin{array}{l}\text { None, no neckline, change harness, massage/stretching, hyperoxygenated peanut oil and rosemary } \\
\text { oil extract }{ }^{\mathrm{a}} \text {, essential oil of wintergreen }{ }^{\mathrm{b}} \text {, peanut oil and rosemary extracts }{ }^{\mathrm{c}} \text {, and emu oil }{ }^{\mathrm{d}} \text {, coat, } \\
\text { heat, heat and ice, decrease travel speed, coats on in any windy weather, change harness, change } \\
\text { position on gangline intermittently }\end{array}$ \\
\hline Carpi and tarsi & $\begin{array}{l}\text { None, massage/stretching, hyperoxygenated peanut oil and rosemary oil extract }{ }^{\mathrm{a}} \text {, essential oil } \\
\text { of wintergreen }{ }^{\mathrm{b}} \text {, peanut oil and rosemary extracts }{ }^{\mathrm{c}} \text {, and emu oil }{ }^{\mathrm{d}} \text {, neoprene wrap }\end{array}$ \\
\hline Lumbar muscles, pelvic limb muscles, stifles & $\begin{array}{l}\text { None, massage/stretching, hyperoxygenated peanut oil and rosemary oil extract }{ }^{\mathrm{a}} \text {, essential oil } \\
\text { of wintergreen }{ }^{\mathrm{b}} \text {, peanut oil and rosemary extractsc, and emu oild, coats, coat and heat, change } \\
\text { harness, change position on gangline intermittently }\end{array}$ \\
\hline Feet (thoracic and pelvic) & $\begin{array}{l}\text { None, trim nails, massage/stretching, menthol }{ }^{\mathrm{e}} \text {, massage/stretching and hyperoxygenated peanut } \\
\text { oil and rosemary oil extract }{ }^{\mathrm{a}} \text {, essential oil of wintergreen }{ }^{\mathrm{b}} \text {, peanut oil and rosemary extracts }{ }^{\mathrm{c}} \text {, } \\
\text { and emu oil }\end{array}$ \\
\hline Swollen feet & $\begin{array}{l}\text { None, trim nails, boot liners, massage, hyperoxygenated peanut oil and rosemary oil extract }{ }^{\mathrm{a}} \text {, } \\
\text { essential oil of wintergreen }{ }^{\mathrm{b}} \text {, peanut oil and rosemary extracts }{ }^{\mathrm{c}} \text {, and emu oil }{ }^{\mathrm{d}}, 50: 50 \text { mix menthol }^{\mathrm{e}} \\
\text { and sulfur powder }\end{array}$ \\
\hline Moist feet & None, drop dog, trim nails, massage, menthole $, 50: 50$ menthol $^{\mathrm{e}}$ and sulfur powder ${ }^{f}$ \\
\hline Splits and cracks in feet & $\begin{array}{l}\text { None, trim nails, zinc oxide with triple antibiotic }{ }^{g} \text {, thuja zinc oxide }{ }^{\mathrm{h}} \text {, iodine } \mathrm{e}^{\mathrm{i}} \text {, petrolatum }{ }^{\mathrm{i}}, \text { menthol }^{\mathrm{e}} \text {, } \\
\text { clindamycin }^{k}\end{array}$ \\
\hline
\end{tabular}

Notes: Various strategies were applied alone or in multiple combinations. There was a wide variability of responses obtained, and thus, all strategies are listed. An association between any strategy with injured and/or dropped dogs could not be detected in this study. Thus, specific recommendations on the application of these strategies cannot be made. ${ }^{a}$ Algyval; Massage Balm for Dogs, Alpine Outfitters, San Clemente, CA, USA; 'Zalox; Ten Squared Racing, Two Harbors, MN, USA; 'Accede; Ten Squared Racing, Two Harbors, MN, USA; dMushers First Aid; Mountain Ridge, Shirley Mills, MN, USA; ' ${ }^{-G o l d ~ B o n d ~ B l u e ~ F o o t ~ P o w d e r ; ~ C h a t t e m ~ I n c ., ~ C h a t a n o o g a, ~ T N, ~ U S A ; ~ f S u l f u r ~ p o w d e r ~}$

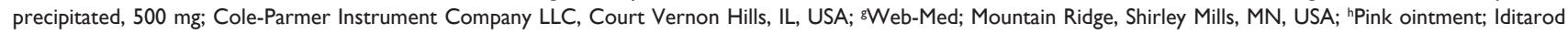
Headquarters, Wasilla, AK, USA; 'lodine I\% ointment; California Veterinary Supply, Pahrump, NV, USA; 'Vaseline jelly, white petrolatum Usp (I00\%); Unilever United States, Inc. Englewood Cliffs, NJ, USA; ' ${ }^{\mathrm{C}}$ lindamycin hydrochloride capsules, USP [300 mg/capsule]; Ranbaxy Inc., a Sun Pharma Company, Princeton, NJ, USA. 


\section{Survival analysis of participating teams}

Two associations between dog-level predictors and time to being dropped could be identified for participating teams. Prerace training distance was associated with an increased DD probability due to carpus injury (HR $=1.61$ $[95 \% \mathrm{CI}=1.09-2.38], P=0.02$ ). Frailty analysis of predictors for which information was available for participating teams and nonparticipating teams (dog age and sex) revealed an association of age with the time to being dropped for any reason $(\mathrm{HR}$ per year increase in age $=0.92[95 \% \mathrm{CI}=0.87-0.97]$, $P=0.03$ ) and when data was stratified for carpus ( $\mathrm{HR}=0.84$ [95\% CI: 0.71 to 0.98 ], $P=0.03$ ) and shoulder injuries ( $\mathrm{HR}=0.92$ [95\% CI $=0.82-1.01], P=0.09$ ), respectively. In addition, sex of the dog was associated with shoulder injuries such that female dogs had a reduced hazard of being dropped due to this reason when compared with male dogs $(\mathrm{HR}=0.70$ [95\% CI $=0.46-1.07], P=0.10)$.

\section{Discussion}

This is the first study to date investigating OI as reasons for DD during a marathon sled dog race. This study was conceived mainly to describe OI and identify potential associations with dogs being dropped from the team/race, in an effort to generate hypotheses for future research.

Approximately one-third (38.3\%) of the entire field of sled dog athletes was dropped. Orthopedic injuries were the cause in $50.6 \%$ of these cases. Fewer dogs were dropped for shoulder injuries if 1) racing at faster speeds, 2) more pre-Iditarod racing distance had been accumulated, or 3) the dog's sex was female as compared to male. Carpal injuries in DDs were associated with more prerace and racing distances traveled. Older and leased dogs had a decreased risk of being dropped. The results of the comparison between participants and nonparticipants showed that the two populations did not differ in characteristics that we were able to assess. Therefore, we believe that the results of the questionnaire are valid for the entire musher population participating in this race. In contrast to previous investigations in canine sports medicine using retrospective questionnaires, ${ }^{8-11}$ all mushers in our study had been informed prospectively and asked to keep this study in their minds during the race, and all data were collected between the finish line of the race up to a maximum of 12 weeks after the race to minimize recall bias.

\section{Variables of significance}

\section{Shoulder, Speed, and Carpus}

Similar to reports on injuries in canine agility sports, ${ }^{8,10,12}$ shoulder and carpal injuries were the most common orthopedic problems and reasons for DDs in this study. In agility dogs, shoulder injuries have been associated with quick turns and changes of direction as well as slippery surfaces. ${ }^{8,9}$ In sled dogs, speed has been anecdotally suggested by mushers to be positively correlated with more OI. To the contrary, we found that increased median speed was associated with a trend of fewer dogs dropped for shoulder injuries. It is possible that slower dog teams are traveling on uneven terrain or trail conditions, including icy surfaces, for example, when crossing parts of the frozen Bering Sea. This could be associated with more stress to the transarticular muscles and ligaments of the shoulder, resulting in more injuries. Although speculative, it is possible that in contrast, dog teams can travel faster on firm flat terrain, resulting in an even stress distribution and more predictable force and impact for the dogs. In addition, the force and torque on the shoulder is potentially greater during slower speeds. At higher speeds, there is more momentum so the shoulder does not have to exert as much force to propel the sled. The statistical model used created comparable results for dogs that traveled different distances. The frailty analysis evaluates time to event and takes into account how long animals were at risk. Therefore, it is possible that our results just indicate that in a team experiencing a smooth race that is completed comparatively fast (with higher median speed), fewer dogs incur shoulder injuries compared with slower teams that take longer to reach the finish line. There was a trend showing that increased racing distance prior to the race was associated with fewer shoulder injuries. It is possible that this is a result of a conditioning and training advantage with shoulder muscles accommodating increased racing distances with more contractile work further preparing the soft tissues for racing. Another mild trend was fewer shoulder injuries in female dogs. This could be attributed to female dogs typically being smaller, lighter, and often used as lead dogs compared with heavier male dogs used as wheel dogs where they are exposed to heavier loads being closer to the sled. With all factors considered, increasing speeds to decrease shoulder injuries is not a recommendation.

Carpal injuries as reasons to be dropped were more frequently seen in dogs with higher prerace conditioning, training, and racing distance, which could have resulted in overuse injury in these dogs. While this hypothesis appears to contradict the slight decrease of DDs for carpal injuries that had undergone more intensive training weeks, one could speculate that these dogs had been trained at shorter distances for a longer period of time. We did not collect data 
on specific training protocols, so this is an unknown. Shorter training distances over a longer period of time before human marathon races have been associated with fewer injuries during the race. ${ }^{13,14}$

\section{Dog age}

Each year, increase of the dog's age was associated with a decreased probability of being dropped for any reason, including for carpal or shoulder injuries. In fact, 1-year old dogs were the most likely ones to become a DD. Likewise, agility dogs with $>4$ years experience were associated with a lower probability of injury. ${ }^{10}$ Sled dog conditioning and training typically starts at 7-9 months of age. Dogs are generally considered experienced "veterans" at 3-4 years of age. It is likely that dogs learn to adjust to both difficult obstacle courses in agility training and possibly to the various trail conditions of a sled dog race course. Such skill acquisition and increase in expertise with experience have been reported for agility dogs ${ }^{15}$ and could result in decreased risk for injury in more experienced and thus, older dogs. However, mushers also frequently drop young dogs early on in the race, not because of a specific injury, but due to a common strategy of running young dogs for only part of the race, to expose them to the fun event, or to prevent them from having a "negative" experience, such as an injury. This likely shifted the number of DDs to the 1-year olds, based on anecdotal discussions with mushers.

\section{Leased dogs}

A trend was found in our study that leased dogs were less likely to be dropped. This could be explained by the fact that most leased dogs are experienced dogs from top-competitor teams that have completed the Iditarod Sled Dog Race at least once. Most leased dogs are provided by highly reputable kennel owners who want to ensure they lease an experienced, proven, durable, and thus older dog.

\section{Variables of no significance Experience level}

While a study on agility dogs reports a lower risk for injury with dog handler's experience of 5-10 years or more years, ${ }^{10}$ we could not detect a difference in the number of DDs between rookie and experienced mushers. It is possible that rookie mushers were more careful traveling at slower speeds regardless of trail conditions as well as providing more rest time compared with experienced mushers. Experienced mushers' knowledge may also have contributed to better prevention and treatment of injuries. In fact, some experienced mushers reported they stop every 30-60 minutes during the race to provide specific preventative injury measures for some dogs.

\section{Checkpoints and trail characteristics}

It was noted that the number of DDs at the checkpoints Rainy Pass and Nikolai were significantly higher compared with other checkpoints. This may be a result from the mountainous terrain crossed in the first part of the race leading to these checkpoints. However, in the current study, there was no statistical association between trail conditions and injuries/ reasons for DDs at a specific checkpoint. This finding was a surprise since we expected to see more carpal injuries associated with steep slopes, for example in the first half of the race and on hard surfaces, or more shoulder injuries with trails that are not firm. In agility dogs, various surfaces such as slippery floors or mats have been associated with increased numbers of injuries. ${ }^{8,9}$ Terrain and racing surfaces have also been associated as important factors implicating injuries in equine cross-country and steeplechase competitions, ${ }^{16,17}$ and although we could not detect similar relations, we encourage further study to obtain additional knowledge regarding trail characteristics and musculoskeletal injuries in marathon sled dogs.

\section{Limitations}

While our study provides valid information on racing sled dogs, never reported before in the veterinary literature and likely helpful for future research in this field, the results should be interpreted with caution. This observational study evaluated one race, and different factors during another year may reveal different results. The results were partly based on a questionnaire yielding subjective information. A limitation of this study is that the questionnaire was developed based on the experience of the authors as trail veterinarians, but the questionnaire was not cognitively validated by a group of similar individuals prior to applying the questionnaire. While the response rate of $40.32 \%$ is higher than what is typically expected for similar questionnaires $(20 \%),{ }^{18}$ responses of $65 \%-75 \%$ are suggested to decrease the source of potential bias and to increase power. ${ }^{19}$ Therefore, limitations include potentially limited internal validity and an overall lack of power. Additionally, it is possible that participants were more open to share their personal experience or were more interested in this project and thus were more likely to complete the survey when compared with nonparticipants. ${ }^{20}$ However, this potential self-selection bias has been shown 
to be outweighed by more complete and higher quality data, compared with randomly selected participants.

It would have been interesting to present specific numbers associated with the risk for injury or being dropped from the race related to speed, training and racing distance, age of dogs, and other variables that could be used as guidelines during training and racing. However, the most appropriate statistical analysis for this study was to use these factors as continuous variables. Therefore, we were not able to determine specific cutoff values.

Variability in diagnosis could have played a role because several veterinarians diagnosed injuries and mushers gave different reasons for DDs. This could not be avoided because one veterinarian could not possibly be present at all checkpoints to evaluate every dog along the entire race. Standardization of reporting was not possible due to various experience levels of the veterinarians in orthopedic diagnoses and general sled dogs sports medicine. Finally, it is possible that the detected results in this study may be related to the level of care provided for each team. For example, it could be possible that faster teams were cared for by a more experienced musher, resulting in smaller numbers of DDs.

\section{Conclusion}

OI, specifically of the shoulder and carpus, are common in marathon sled dogs. Injury risk may be speed-related and decreases with increasing age of the dog. Further study of environmental, dietary, and trail conditions in sled dog racing orthopedic research is needed.

\section{Acknowledgments}

The authors thank all participating mushers, the Iditarod Committee, Zack Steer, Robert Bundtzen, Jay Barry, and David Frost for their general support and editorial help, as well as IonEarth Global Position Tracking - Microline Technology Corporation for providing the GPS data used in this study. This study was presented in part at the ISDVMA Conference, Banff, Alberta, Canada, September 28-30, 2012.

\section{Disclosure}

The authors report no conflicts of interest in this work.

\section{References}

1. Iditarod.com [homepage on the Internet]. Wasilla: Iditarod Trail Committee, Inc. Available from: http://iditarod.com/. Accessed April 29, 2015 .
2. The official map of the Iditarod. [webpage on the Internet]. Iditarod Committee IT, 2008. Available from: http://d3r6t1k4mqz5i.cloudfront. net/wp-content/uploads/2013/03/route_southern.jpg?50a80c2008/. Accessed April 29, 2015.

3. Nelson S. Checkpoint protocol and dog care [webpage on the Internet]. Wasilla: Iditarod Trail Committee, Inc. Available from: http://iditarod. com/teacher/checkpoint-protocol-and-dog-care-by-stuart-nelson-jr$\mathrm{dvm} /$. Accessed April 29, 2015.

4. Race rules of the Iditarod. Website page on: Iditarod.com [webpage on the Internet]. Wasilla: Iditarod Trail Committee, Inc. Available from: http://iditarod.com/race/rules/. Accessed April 29, 2015.

5. Long RD. Treatment of common injuries in endurance racing sled dogs. Comp Contin Educ Pract Vet. 1993;15:434-437.

6. Von Pfeil DJF, Griffitts C. Injuries to the axial skeleton of sled dogs. In: Von Pfeil DJF, Lee J, Thompson S, Hinchcliff K, editors. Musher and Veterinary Handbook. 3rd ed. Raleigh: International Sled Dog Veterinary Medical Association/Lulu Press Inc NC; 2015:127-145.

7. Vanek JA. Paw lesions in sled dogs. In: Von Pfeil DJF, Lee J, Thompson S, Hinchcliff K, editors. Musher and Veterinary Handbook. 3rd ed. Raleigh: International Sled Dog Veterinary Medical Association/Lulu Press Inc NC; 2015:150-157.

8. Levy M, Hall C, Trentacosta N, Percival M. A preliminary retrospective survey of injuries occurring in dogs participating in canine agility. Vet Comp Orthop Traumatol. 2009;22(4):321-324.

9. Cullen KL, Dickey JP, Bent LR, Thomason JJ, Moens NM. Survey-based analysis of risk factors for injury among dogs participating in agility training and competition events. J Am Vet Med Assoc. 2013;243(7): 1019-1024.

10. Cullen KL, Dickey JP, Bent LR, Thomason JJ, Moens NM. Internetbased survey of the nature and perceived causes of injury to dogs participating in agility training and competition events. J Am Vet Med Assoc. 2013;243(7):1010-1018.

11. Houlton JE. A survey of gundog lameness and injuries in Great Britain in the shooting seasons 2005/2006 and 2006/2007. Vet Comp Orthop Traumatol. 2008;21(3):231-237.

12. Baltzer W. Sporting Dog Injuries [serial on the Internet]. 2012; [about 7 p.] Available from: http://veterinarymedicine.dvm360.com/sportingdog-injuries/. Accessed April 29, 2015.

13. Bovens AM, Janssen GM, Vermeer HG, Hoeberigs JH, Janssen MP, Verstappen FT. Occurrence of running injuries in adults following a supervised training program. Int J Sports Med. 1989;10(Suppl 3): S186-S190.

14. Rasmussen $\mathrm{CH}$, Nielsen RO, Juul MS, Rasmussen S. Weekly running volume and risk of running-related injuries among marathon runners Int J Sports Phys Ther. 2013;8(2):111-120.

15. Helton WS. Skill in expert dogs. J Exp Psychol Appl. 2007;13(3): $171-178$.

16. Bailey CJ, Reid SW, Hodgson DR, Bourke JM, Rose RJ. Flat, hurdle and steeple racing: risk factors for musculoskeletal injury. Equine Vet J. 1998;30(6):498-503.

17. Murray JK, Singer ER, Morgan KL, Proudman CJ, French NP. The risk of a horse-and-rider partnership falling on the cross-country phase of eventing competitions. Equine Vet J. 2006;38(2):158-163.

18. Kelley K, Clark B, Brown V, Sitzia J. Good practice in the conduct and reporting of survey research. Int J Qual Health Care. 2003;15(3): 261-266.

19. Sitzia J, Wood N. Response rate in patient satisfaction research: an analysis of 210 published studies. Int J Qual Health Care. 1998;10(4): 311-317.

20. Walsh JP, Kiessler S, Sproull LS, Hesse BW. Self-selected and randomly selected respondents in a computer network survey. Public Opin $Q$. 1992;56:241-244. 


\section{Supplementary material}

1. Years of experience as a musher in marathon sled-dog races?

2. Your age?

3. How many Marathon sled-dog races have you participated in? Long Distance races? (Note: For this study, a marathon sled dog race is defined as a race of $1000+$ miles. Long distance racing is defined as races of $300+$ miles). Marathon? Long Distance?

4. Do you consider yourself a full-time musher ( ) or do you have a second job (__ $)$ ?

5. How many months per year do you do nothing but preparing for the Iditarod (1-12)?

6. What were your goals for the 2011 Iditarod at race start? Finish in the Top 5: _ Top 10: _ Top 30: __ Finish; no matter what place:

7. How many years have you been a competitive musher?

8. Duration of training with intensity similar to the last $\mathbf{2}$ months prior to race start? (in weeks)

9. How many pre-race training miles did your dogs accumulate?

10. How many races have you completed during this current race season?

11. How many miles have you accumulated during races during this current race season?

12. INJURY PREVENTION: List your routine injury preventative measures utilized at each checkpoint (for example: coats, blankets, massage, wraps, warm packs, ointments, nothing ...) No injury prevention measures of any kind (Check if appropriate):

Neck: Shoulder: Front leg muscles: Wrist: Front Feet: Low Back: Hips: Back leg muscles: Stifles (knees): Hock: Back Feet:

13. How many minutes do you dedicate on average to injury preventative measures:

14. INJURY TREATMENT: What are the injury treatment protocols you utilize at each checkpoint or when you stop (coats, blankets, massage, wraps, warm packs, ointments, nothing, ...) for injuries that are not immediately a reason to drop a dog? (Note: To prevent confusion - Question 12 is about Prevention of injuries. Question 14 is about $\underline{\text { Treatment }}$ of injuries)

No injury treatment measures are taken (check if appropriate):

The only treatment measures taken are those of the veterinarian (check if appropriate)

No injury prevention measures of any kind (Check if appropriate):

Neck: Shoulder: Front leg muscles: Wrist: Front Feet: Low Back:

Hips:___ Back leg muscles:_____tifles (knees):_Hock: Back Feet:

15. How many minutes do you dedicate on average to injury treatment?

16. What type of diet do you feed your dogs during the three months prior to the race? (try to be as specific as you can if home cooked; list the brands of the high performance dog food you feed, include ulcer preventatives, vitamins and other supplements); use back side for additional comments.

17. What changes do you make (if any) to the diet during the last few days before the race and during the race? (try to be as specific as you can if home cooked; list the brands of the high performance dog food you feed, include acid suppressants, vitamins and other supplements).

Last few days:

During the race:

18. How many dogs in your team are leased?

19. How long did you have the chance to work with the leased dogs before the race started?

20. Type of harness used: H-back:__ X-back:___ Collared-Neck Harness: Other (describe)

21. Trail conditions: *Please note: Trail conditions are difficult to specify. We would like you to get your opinion on the trail conditions. Opinion being the key word as two mushers may have very different experiences on the same section of trail. Trail conditions are generalized into five descriptions: 
Little to no snow, b) Hard packed snow, c) Soft, unconsolidated snow, d) Open water/overflow, e) Bare ice, f) other. (Please assign a percentage to each category, and percentages should total 100\%. Example: Rainy Pass - Rohn: c: 80\%, d) $10 \%$, e) $10 \%$ ); use back side if needed.

Willow-Yentna: Yentna-Skwentna: Skwentna-Finger Lake: Finger Lake-Rainy Pass: Rainy

Pass-Rohn: Rohn-Nikolai: Nikolai-McGrath: McGrath-Takotna:

Takotna-Ophir: Ophir-Iditarod: Iditarod-Shageluk: Shageluk-Anvik:

Anvik-Grayling: ___ Grayling-Eagle Island: Eagle Island-Kaltag: Kaltag-Unalakleet:

Unalakleet-Shaktoolik:__Shaktoolik-Koyuk: Koyuk-Elim: Elim-White Mountain: White

Mountain-Safety: Safety-Nome:

22. Do you use necklines or not? Yes No

23. Pertinent data of dropped $\operatorname{dog}(\mathrm{s})$ : Name: Age: Sex: Weight $(\mathrm{kg})$ : Reason to drop:

Figure SI Questionnaire for mushers.*

\section{Publish your work in this journal}

Veterinary Medicine: Research and Reports is an international, peer-reviewed, open access journal publishing original research, case reports, editorials, reviews and commentaries on all areas of veterinary medicine. The manuscript management system is completely online and includes a very quick and fair peer-review system.
Visit http://www.dovepress.com/testimonials.php to read real quotes from published authors. 